\title{
Liver-Directed Therapies in Patients With Advanced Neuroendocrine Tumors
}

\author{
Natalie B. Jones, $\mathrm{MD}^{\mathrm{a}}$; Manisha H. Shah, $\mathrm{MD}^{\mathrm{b}}$; and Mark Bloomston, MDa
}

\begin{abstract}
Neuroendocrine tumors (NETs) are increasing in incidence. Incidental NETs that may have little clinical significance, such as gastric and rectal primaries, are often identified because of increased screening efforts and advanced imaging modalities. Although NETs are biologically indolent cancers, many patients present with incurable metastatic disease to the liver at initial diagnosis. Some literature suggests a delay averaging almost 5 years in making the correct diagnosis based on clinical symptoms. Although surgical resection offers the only potentially curative therapy, liver-directed therapies, such as embolization and ablation, offer effective alternatives to control symptoms and potentially impact overall survival. This article reviews the latest liver-directed approaches to the management of advanced NETs. (JNCCN 2012;10:765-774)
\end{abstract}

\section{Medscape: Continuing Medical Education Online}

\section{Accreditation Statement}

This activity has been planned and implemented in accordance with the Essential Areas and policies of the Accreditation Council for Continuing Medical Education through the joint sponsorship of Medscape, LLC and JNCCN - The Journal of the National Comprehensive Cancer Network. Medscape, LLC is accredited by the ACCME to provide continuing medical education for physicians.

From the Departments of aSurgery and ${ }^{\mathrm{b}} \mathrm{Hematology/Oncology,} \mathrm{The} \mathrm{Ohio}$ State University, Columbus, Ohio.

Submitted December 1, 2011; accepted for publication February 8, 2012. Correspondence: Mark Bloomston, MD, Department of Surgery, Division of Surgical Oncology, The Ohio State University, M-256 Starling Loving Hall, 410 West 10th Avenue, Columbus, $\mathrm{OH} 43210$.

E-mail: Mark.Bloomston@osumc.edu

\section{EDITOR}

Kerrin M. Green, MA, Assistant Managing Editor, Journal of the National Comprehensive Cancer Network

Disclosure: Kerrin M. Green, MA, has disclosed no relevant financial relationships.

\section{AUTHORS AND CREDENTIALS}

Natalie B. Jones, MD, Department of Surgery, The Ohio State University, Columbus, Ohio

\begin{abstract}
Medscape Medscape, LLC designates this Journal-based CME activity for a maximum of 1.0 AMA PRA Category 1 Credit(s) ${ }^{\mathrm{TM}}$. Physicians should claim only the credit commensurate with the extent of their participation in the activity.

All other clinicians completing this activity will be issued a certificate of participation. To participate in this journal CME activity: (1) review the learning objectives and author disclosures; (2) study the education content; (3) take the post-test with a $70 \%$ minimum passing score and complete the evaluation at www.medscape. org/journal/jnccn; (4) view/print certificate.
\end{abstract}

Release date: June 4, 2012; Expiration date: June 4, 2013.

\section{Learning Objectives}

Upon completion of this activity, participants will be able to:

- Distinguish the most important prognostic factor for survival in cases of NETs

- Analyze surgical options for the treatment of liver metastases associated with NETs

- Assess the use of embolization of liver metastases associated with NETs

- Evaluate other treatment modalities of liver metastases associated with NETs

Neuroendocrine tumors (NETs) are rare, with a rising incidence over the past few decades of 5 to 7 cases per 100,000.1,2 Gastroenteropancreatic NETs have the sec-

Disclosure: Natalie B. Jones, MD, has disclosed no relevant financial relationships.

Manisha H. Shah, MD, Department of Hematology/Oncology, The Ohio State University, Columbus, Ohio

Disclosure: Manisha H. Shah, MD, has disclosed no relevant financial relationships.

Mark Bloomston, MD, Department of Surgery, The Ohio State University, Columbus, Ohio

Disclosure: Mark Bloomston, MD, has disclosed no relevant financial relationships.

\section{CME AUTHOR}

Charles P. Vega, MD, Health Sciences Clinical Professor; Residency Director, Department of Family Medicine, University of California, Irvine Disclosure: Charles P. Vega, MD, has disclosed no relevant financial relationships. 
Jones et al.

ond highest prevalence of all gastrointestinal cancers. Not surprisingly, the liver is the most common site of metastases, in addition to regional lymph nodes. As many as $75 \%$ of small bowel NETs and $30 \%$ to $85 \%$ of pancreatic NETs present either synchronous or metachronous with liver metastases. ${ }^{1,3}$ In addition, $5 \%$ to $10 \%$ of patients with NETs present with liver metastases as their initial presentation, with primaries of unknown origin. It has been shown that hepatic metastases are the most important prognostic indicator of survival in patients with NETs regardless of the primary site. ${ }^{4}$ Historically, 5-year survival rates for untreated neuroendocrine liver metastases range from $13 \%$ to $54 \%$ compared with $75 \%$ to $99 \%$ in patients without liver metastases. ${ }^{5,6}$ Progression of liver metastases associated with bony metastases can often be seen in NETs and is an indicator of aggressive disease. Therefore, distinction is often made between treatment modalities based on aggressiveness of tumor and extent of extrahepatic metastasis. The presence of liver metastases and their patterns of distribution are prognostic indicators. ${ }^{7,8}$

Currently, consensus is lacking regarding how NET liver metastases should be managed, specifically regarding the goals of therapy (curative vs. palliative), indication for initiation of treatment (tumor burden, symptoms), and optimal means to achieve these objectives (systemic therapy, surgery, percutaneous interventions). ${ }^{9}$ This article focuses on liver-directed therapies for metastatic NETs, specifically the role of cytoreductive hepatectomy, liver transplantation, and percutaneous interventions (e.g., ablation, chemoembolization, radioembolization). Given the propensity for poorly differentiated tumors to be treated with systemic therapy, this discussion is limited to the management of low-grade (i.e., well-differentiated and moderately differentiated) tumors.

\section{Surgical Resection}

Surgical resection of hepatic NET metastases, when feasible, is the optimal treatment; however, only $10 \%$ to $20 \%$ of patients with liver metastases are candidates for any type of surgical resection. In addition, surgical morbidity and mortality needs to be taken into consideration owing to the often indolent biology. Overall survival after hepatic resection differs among reported series, from $46 \%$ to $86 \%$ at 5 years and $35 \%$ to $79 \%$ at 10 years, ${ }^{10}$ reflecting diverse patient selection, het- erogeneity of tumor biology, and often multiple treatment modalities. Outcomes after hepatic resection for NETs take into account overall survival but must also consider symptom palliation. As one might expect, having hepatic tumor burden amenable to surgical resection suggests more favorable biology. This is reflected in median overall survival ranging from $27^{11}$ to 78 months ${ }^{12}$ in patients who undergo hepatic resection compared with $27^{11}$ and 17 months ${ }^{12}$ in patients with unresectable tumor burden.

Yao et al..$^{13}$ used defined criteria to direct patients to either surgical resection or chemoembolization. In the group who underwent surgery, all of the tumors were completely resected without operative mortality, and the overall 5-year survival rate was $70 \%$. Survival was prolonged in the subset of patients who were able to undergo potentially curative resections ${ }^{14}$; however, symptom improvement can be seen in patients undergoing curative and palliative resection. ${ }^{14,15}$ It is important to distinguish between surgical resection with the goal of complete tumor removal (i.e., curative intent) and palliative cytoreductive hepatectomy. When cytoreductive hepatectomy is undertaken (i.e., removal of at least $90 \%$ of hepatic tumor burden), hormone-related symptom relief ranges on average from 6 to 24 months. ${ }^{14,16}$ A more recent study by Osborne et al ${ }^{17}$ specifically compared outcomes of hepatectomy with curative $(\mathrm{N}=38)$ or cytoreductive $(\mathrm{N}=23)$ intent and embolization $(\mathrm{N}=59)$ for patients with symptomatic NET hepatic metastases. Surgical resection resulted in more durable symptom control compared with embolization (32 vs. 22 months), and significantly prolonged survival, particularly when undertaken with curative intent (median, 50 vs. 32 months for cytoreduction and 24 months for embolization).

Several retrospective series have sought to characterize prognostic factors that may help in patient selection for resection of liver metastases. Yao et al. ${ }^{13}$ showed that resection of the primary tumor first, followed by liver resection of 4 metastases or less significantly improved disease-free survival (46 vs. 20 months in patients with $>4$ metastases) after hepatic resection. However, Sarmiento et al. ${ }^{18}$ advocated the benefit of synchronous resection of pancreatic NETs and hepatic metastases (71\% overall survival at 5 years) with a tendency toward improved survival in patients who underwent complete resection of all gross disease. Norton et al. ${ }^{19}$ reported 
Liver-Directed Therapies in Advanced NETs

a $60 \%$ 5-year overall survival for patients undergoing combined resection of advanced NETs and liver metastases, despite $100 \%$ recurrence within 7 years. Even the largest reported series from Mayo Clinic on hepatic resection for NETs showed high recurrence rates $(76 \%)$ for completely resected liver metastases, with a median time to recurrence of 30 months, although improved when compared with $91 \%$ and 16 months in the incompletely resected group. ${ }^{15}$ Similar to other studies focusing on resection of hepatic metastases, complete resection was an important factor influencing recurrence. ${ }^{20}$ However, the high recurrence rates despite complete resection levels the playing field in favor of performing more incomplete resections to preserve more liver parenchyma. In addition, whether to leave the primary tumor intact when dealing with metastatic disease to the liver remains to be determined.

Only a few recent studies have attempted to compare surgical resection with other interventional therapies or best medical supportive care. In addition to Yao et al., ${ }^{13}$ Chamberlain et al. ${ }^{21}$ compared surgical resection with hepatic artery embolization and medical therapy in a group of 85 patients, 38 of whom had extrahepatic disease. Overall 3- and 5 -year survivals for the entire cohort were $61 \%$ and $53 \%$, respectively. On subdividing the patients into surgery, embolization, and medical therapy, survival was prolonged in the group undergoing surgical resection. However, surgery was only beneficial in patients with less than $75 \%$ tumor involvement of liver. ${ }^{20}$ Other studies emphasize the benefit of surgical resection (> 96 months median survival and $72 \%$ 5 -year survival) compared with regional therapy ( 50 months median survival and 50\% 5-year survival); however, these therapies were only beneficial in patients with less than 50\% liver involvement. ${ }^{21}$ Another more recent retrospective review of patients with metastatic NETs to the liver compared the combination of resection and chemoembolization with either treatment alone. The mean overall survival was greatest in the combination group (148 months; $P=.001$ ) compared with surgery alone (131 months) or chemoembolization alone ( 42 months). By multivariate analysis, age and treatment modalities were independent predictors of overall survival. ${ }^{22}$

\section{Liver Transplantation}

Aside from surgical resection, liver transplantation for metastatic NETs is another alternative approach with curative intent or refractory symptoms not amenable to alternative therapies, although its efficacy remains to be proven. Initially, transplant has been offered to patients whose liver disease is not amenable to resection because of the slow-growing tendencies of NETs.

The initial series report data on generally unselected patients with poor overall and recurrence-free survivals. Le Treut et al. ${ }^{23}(\mathrm{~N}=85)$ and Lehnert. ${ }^{24}(\mathrm{~N}=103)$ reported 5 -year overall survival rates of $36 \%$ to $47 \%$ and 5 -year recurrence-free survival rates ranging from $17 \%$ to $24 \%$. Le Treut et al. ${ }^{23}$ showed that survival was improved for patients with carcinoid tumors versus noncarcinoid tumors (69\% vs. $8 \%$, respectively, at 5 years). A larger single institution series on transplantation for NET hepatic metastases reported 5- and 10-year overall survival rates of $80 \%$ and $50 \%$, respectively. ${ }^{25}$ Increased proliferation as measured by $\mathrm{Ki}-67$ immunohistochemistry of $5 \%$ or greater and aberrant expression of E-cadherin identified a subset of patients with a less-favorable prognosis after hepatic transplantation for metastatic NETs. Dousset et al. ${ }^{26}$ showed the importance of patient selection when considering liver transplantation for metastatic NETs, suggesting that patients with extrahepatic and indolent disease (in contrast to rapid tumor growth unresponsive to alternative therapy options) be excluded.

The most recent report on liver transplantation for metastatic NETs by Le Treut et al. ${ }^{27}$ confirmed that extensive liver tumor burden and duodenopancreatic primary tumor location negatively impacts 5 -year overall survival ( $12 \%$ vs. $68 \%$ in the group without the criteria mentioned earlier). Frilling et al. ${ }^{28}$ excluded patients for transplantation by using high $\mathrm{Ki}-67$, unresectable extrahepatic disease, and presence of carcinoid heart disease. One additional group used even more stringent criteria, including tumor grade, surgical resection before transplantation, tumor burden within liver, disease stability for minimum of 6 months, and age to obtain $90 \%$ overall survival and $77 \%$ recurrence-free survival at 5 years. ${ }^{29}$

In summary, the role of liver transplantation in metastatic NETs is still being defined and will continue to evolve as the criteria for transplantation are modified. Living related liver donors may play an 
Jones et al.

increasing role in the future, increasing the donor pool and expanding the number of patients listed for transplant. Also, the prognosis for pancreatic NETs compared with midgut NETs differs immensely, further emphasizing the need for prospectively gathered data and better-defined criteria for transplantation.

\section{Transcatheter Arterial Embolization and Chemoembolization}

Because of the dual blood supply of the liver and hypervascularity of liver metastases supplied primarily by the hepatic artery, transcatheter arterial embolization (TAE) and transcatheter arterial chemoembolization (TACE) offer excellent strategies for inducing tumor ischemia. TAE and TACE have been used to decrease tumor burden, palliate symptoms, and reduce hormone levels in patients with metastatic NETs. Bland embolization was used first until a report from Moertel et al. ${ }^{30}$ was published, which showed a higher disease regression rate and a longer duration of regression with systemic chemotherapy after TAE than with TAE alone, which prompted the increase in TACE procedures. Controversy still exists regarding whether chemoembolization is better than embolization alone, the extent of liver volume that should be embolized during a single treatment, chemotherapeutic regimens, and timing of the procedure (early or late) in the disease course. Multiple studies showed marginal difference in TAE versus TACE in median overall survival, symptom improvement, morbidity, and mortality. ${ }^{31-34}$ Despite the unclear evidence favoring TACE over TAE, Gupta et al. ${ }^{35}$ showed a trend toward prolonged survival (31.5 vs. 18.2 months) and an improved radiologic response rate $(50 \%$ vs. $25 \%)$ in patients with metastatic islet cell tumors undergoing TACE compared with TAE. The advantage of TACE over TAE was not seen in metastatic carcinoid tumors. However, overall survival is generally improved postembolization in metastatic carcinoid tumors compared with islet cell tumors, with median survival ranging from 27 to 80 months versus 9 to 20 months $^{30,36}$ (Table 1). Given that most studies evaluating intraarterial therapies combine pancreatic NETs and carcinoid tumors, direct comparisons between tumor types and treatment modalities are difficult, if not impossible.

Multiple groups have studied the association between percent of overall liver tumor burden and rates of overall survival and radiologic response. Several groups advocate liver tumor burden of greater than $50 \%$ to $75 \%$ as a relative contraindication for TACE because of elevated mortality rates secondary to liver failure. ${ }^{35,37,38}$ Gupta et al. ${ }^{35}$ showed lower median survival durations and response rates in patients with greater than $75 \%$ liver tumor involvement who underwent TACE; however, most patients were able to be treated safely and successfully when only a small portion of the liver was embolized in each treatment. Current trends are for either lobar (selective) or segmental (highly selective) embolization to minimize the risk of carcinoid crisis, acute liver failure, and tumor lysis syndrome. Portal vein thrombosis or underlying hepatic insufficiency are other relative exclusion criteria requiring extreme caution and highly selective embolization. . $^{37,39}$

TACE has acceptable peri-interventional morbidity (23\%) and mortality (5\%), as reported by the authors' group, with documented symptom palliation durable for a median of 13 months in $92 \%$ of patients. ${ }^{39}$ The duration of symptom response was likely underestimated, because most patients report better symptom control for 2 to 3 years after TACE compared with pre-TACE, despite progression. This has been validated in a more recent study suggesting that TAE or TACE should be used in the setting of tumors that are unresectable or not amenable to ablation, with a reduction in tumor burden in $50 \%$ of patients and 5 -year survival rate of $60 \%$. The symptomatic response rate was $90 \%$ with a median duration of 2 years. ${ }^{40}$ Although the role of liver-directed regional therapies for metastatic NETs is well established, consensus is lacking regarding the techniques and chemotherapeutic agents (see Table 1).

A newer approach uses drug-eluting beads loaded with doxorubicin (DEBDOX) to combine chemotherapy and embolization. Only a few small series have been reported in the literature thus far, but results are promising in terms of consistent delivery of drug and ease of use $\mathrm{e}^{41-43}$ (Table 2). Biliary toxicity with DEBDOX has been documented as a rare but potentially fatal side effect, and precautions must be taken to recognize this complication. ${ }^{44}$ Previous pancreaticoduodenectomy (Whipple) or biliary instrumentation (sphincterotomy, stent placement, biliary-enteric bypass) is also associated with an increased incidence of liver abscess after TACE and TAE..$^{45}$ 
Liver-Directed Therapies in Advanced NETs

\begin{tabular}{|c|c|c|c|c|}
\hline Year & Authors & N (Procedure) & Survival & Comments \\
\hline 2005 & Gupta et al. ${ }^{35}$ & 123 (TAE/TACE) & $\begin{array}{l}\text { pancNET: } 23 \mathrm{mo} \\
\text { Carcinoid: } 34 \mathrm{mo}\end{array}$ & $\begin{array}{l}\text { Trend toward improved survival in pancNET undergoing } \\
\text { TACE vs. TAE } \\
\text { Carcinoid showed improved OS compared with pancNET }\end{array}$ \\
\hline 2006 & Strosberg et al. ${ }^{67}$ & 84 (TAE) & $36 \mathrm{mo}$ & $\begin{array}{l}\text { Clinical and radiologic response for metastatic pancNET } \\
\text { and carcinoid }\end{array}$ \\
\hline 2007 & Ho et al. ${ }^{68}$ & 46 (TAE/TACE) & $42 \mathrm{mo}$ & $\begin{array}{l}\text { EHD and unresected primary tumor not contraindication } \\
\text { to TACE or TAE }\end{array}$ \\
\hline 2007 & Bloomston et al. ${ }^{39}$ & 122 (TACE) & $33 \mathrm{mo}$ & $\begin{array}{l}\text { TACE offers good symptomatic response and long-term } \\
\text { survival } \\
\text { TACE should be used cautiously in patients with } \\
\text { significant liver tumor burden }\end{array}$ \\
\hline 2008 & Pitt et al. ${ }^{69}$ & 100 (TAE/TACE) & $25 \mathrm{mo}$ & $\begin{array}{l}\text { OS same for TAE vs.TACE } \\
\text { Resection of primary tumor predicted survival according } \\
\text { to MVA }\end{array}$ \\
\hline 2008 & Christante et al. ${ }^{70}$ & 77 (HAl/TACE) & $39 \mathrm{mo}$ & Advocate use of HAl with TACE \\
\hline 2009 & Sward et al. ${ }^{40}$ & 107 (TAE) & $56 \mathrm{mo}$ & $\begin{array}{l}\text { All midgut carcinoids: symptom control and prolonged } \\
\text { survival in biochemically responsive tumors }\end{array}$ \\
\hline 2011 & Dong and Carr ${ }^{71}$ & 123 (TACE) & $39 \mathrm{mo}$ & $\begin{array}{l}\text { Low albumin negatively impacts prognosis by MVA } \\
\text { TACE useful for tumor size reduction and symptom } \\
\text { palliation, and can prolong survival }\end{array}$ \\
\hline
\end{tabular}

Abbreviations: EHD, extrahepatic disease; HAI, isolated hepatic arterial infusion; MVA, multivariate analysis; OS, overall survival; pancNET, pancreatic neuroendocrine tumors; TACE, transarterial chemoembolization; TAE, transarterial embolization.

Aside from TAE or TACE, isolated liver perfusion has been performed via operative and percutaneous techniques for patients with isolated and unresectable liver metastases in the setting of NET. Patients with both ocular melanoma and metastatic NETs often develop either isolated or diffuse liver metastases without additional sites of extrahepatic disease. The goal of hepatic perfusion is to deliver high-dose therapeutic agents to the liver via the hepatic arterial system to improve efficacy and eliminate systemic side effects. ${ }^{46}$ Currently, limited data have been published for isolated hepatic perfusion using either melphalan or tumor necrosis factor, with one study of 14 patients reporting an overall response rate of $50 \%, 7$-month progression-free survival, and 48 months overall survival. ${ }^{47}$ The role for isolated hepatic perfusion will continue to develop as more patients are recruited into cooperative institution clinical trials for patients with well-defined liver tumor burden and normal synthetic liver function.

\section{Radioembolization}

Two radioactive microsphere devices are currently approved for the treatment of unresectable hepato- cellular carcinoma (TheraSpheres, MDS Nordion, Ottawa, Canada) and unresectable colorectal cancer metastases to the liver (SIR-Spheres, Sirtex, Woburn, Massachusetts) with adjuvant floxuridine. Both of these devices use yttrium-90 $\left({ }^{90} \mathrm{Y}\right)$ as a pure $\beta$-emitter, with a mean tissue penetrance of $2.5 \mathrm{~mm}$. As an intraarterial regional liver therapy, radioembolization is similar to TACE. High doses of radiation can be delivered to the tumor via the hepatic artery, with relative sparing of normal liver parenchyma. ${ }^{9}$ Results from Canada, Australia, Hong Kong, and the United States for other tumor types using radioembolization show acute and subacute toxicities that are more tolerable than those associated with other hepatic embolization procedures.

Radioembolization has evolved into another effective treatment approach for neuroendocrine liver metastases as reported in the recent literature. ${ }^{48-50}$ Radioembolization used for metastatic NETs was reported to have a partial response in up to $60 \%$ of cases, with median survival ranging from 28 to 70 months and symptomatic relief for median duration of 12 months. King et al..$^{51}$ combined radioembolization with systemic 5-FU in 34 patients with unresect- 
Jones et al.

\begin{tabular}{|c|c|c|c|c|}
\hline Year & Author & $\mathbf{N}$ & Outcome & Comments \\
\hline 2008 & de Baere et al. ${ }^{41}$ & 20 & PFS, $15 \mathrm{mo}$ & TACE with DEBs (doxorubicin) is effective and well-tolerated \\
\hline \multirow[t]{2}{*}{2011} & Whitney et al. ${ }^{42}$ & 28 & PFS, $18 \mathrm{mo}$ & TACE with DEBs (doxorubicin) is safe and effective \\
\hline & & & $\mathrm{OS}, 25 \mathrm{mo}$ & Cost must be taken into consideration \\
\hline \multirow[t]{2}{*}{2011} & Gaur et al. ${ }^{43}$ & 18 & PFS, 14 mo & 2 biliary injuries \\
\hline & & & & TACE with doxorubicin DEBs is reasonable alternative to TACE or TAE \\
\hline
\end{tabular}

Abbreviations: DEBs, drug-eluting beads; OS, overall survival; PFS, progression-free survival; TACE, transarterial chemoembolization; TAE, transarterial embolization.

able liver metastases from NETs and reported $50 \%$ radiologic response, decreased chromogranin $\mathrm{A}$ levels in over $50 \%$ of patients, and mean survival of 27.6 months. In 2005, McStay et al..$^{52}$ reported intraarterial use of ${ }^{90} \mathrm{Y}$ combined with long-acting octreotide (lanreotide) administered directly to liver metastases in a total of 23 patients with large-volume disease (> 85\% tumor burden). Stable disease was reported in $63 \%$, with $60 \%$ improvement in biologic markers and a $63 \% 1$-year survival rate..$^{52} \mathrm{~A}$ small $(\mathrm{N}=9)$ study showing a greater than $60 \%$ partial response in patients with metastatic NETs treated with radioembolization (33\% stable disease) with an almost 50\% reduction in liver tumor volume and an estimated time to progression of 11.1 months,${ }^{53}$ is in line with a more recent study of 40 patients with NET liver metastases treated with radioembolization, with at least a partial radiographic response in greater than $60 \%$ of patients based on size and necrosis ${ }^{54}$ (Table 3).

The potential role for radioembolization remains mainly palliative in nature, with some disease stabilization and symptom control in several reported smaller series. The timeline for use of radioembolization remains to be determined through larger prospective case series and more uniform patient populations.

\section{Thermal Ablation}

Over the past 2 decades, various devices have been developed to ablate tumors using heat (radiofrequency and microwave) or cold (cryoablation). Although the pros and cons of each modality are beyond the scope of this article, each has been used in the context of unresectable hepatic NET metastases. Radiofrequency (RFA) or microwave (MWA) ablation can be facilitated via image-guided percutaneous, laparoscopic, or open surgical approaches, either as a single procedure or combined with other modalities.
Some studies have advocated that an open surgical or laparoscopic approach is superior to percutaneous approaches, irrespective of the size of the lesion. ${ }^{55,56}$

In one of the largest reported series of neuroendocrine liver metastases using laparoscopic RFA in 63 patients to treat 452 liver lesions, the 30 day morbidity was $5 \%$ and mortality $0 \%$. The mean tumor size was $2.3 \mathrm{~cm}(0.5-10 \mathrm{~cm})$ and the mean number of lesions treated was 6 (range, 1-16). Median survival was 3.9 years from the time of first RFA session and most favorable in patients with dominant liver lesions measuring less than $3 \mathrm{~cm} .{ }^{57}$ Several smaller RFA series for liver metastases from NETs report hormone-related symptom relief after RFA in $69 \%$ to $80 \%$ with a duration of 10 to 35 months, and local control in as many as $74 \% .{ }^{58-60} \mathrm{RFA}$ is often used in combination with TAE or TACE and has been shown to provide superior results for large hepatocellular carcinomas, which may be applicable to management of NET liver metastases. ${ }^{61,62}$ Alternatively, MWA uses electromagnetic microwaves to agitate water molecules in the surrounding tumor tissue causing cell death through coagulation necrosis. This technique may be superior to RFA when larger or multifocal tumors are involved. ${ }^{63}$

Current limitations of RFA are that complete tumor necrosis is difficult to achieve in tumors larger than $3 \mathrm{~cm}$ in diameter. RFA has been used with good results and minimal morbidity for treating patients with advanced neuroendocrine disease, especially when combined with other techniques, such as resection, TACE, or radioembolization, in an effort to spare hepatic parenchyma. $^{64,65}$ Laparoscopic approaches guided by intraoperative ultrasound facilitate the greatest tumor ablation, with minimal morbidity and low rates of tumor recurrence, thereby creating a role for RFA in certain patients who are not surgical 
Liver-Directed Therapies in Advanced NETs

\begin{tabular}{|c|c|c|c|c|}
\hline Year & Author & $\mathbf{N}$ & Outcome & Comments \\
\hline \multirow[t]{2}{*}{2008} & \multirow[t]{2}{*}{ Kennedy et al. ${ }^{48}$} & \multirow[t]{2}{*}{148} & $\mathrm{RR}, 63 \%$ & No grade 4 toxicities \\
\hline & & & OS, $70 \mathrm{mo}$ & $\begin{array}{l}\text { Safe and high response rates, even with extensive liver } \\
\text { tumor burden (multi-institution) }\end{array}$ \\
\hline \multirow[t]{4}{*}{2008} & \multirow[t]{4}{*}{ King et al. ${ }^{51}$} & \multirow[t]{4}{*}{34} & $\mathrm{RR}, 50 \%$ & Radioembolization + 7-day systemic infusion of 5-FU \\
\hline & & & OS, $29 \mathrm{mo}$ & $\begin{array}{l}1 \text { death from liver dysfunction; } 2 \text { patients with radiation } \\
\text { gastritis; } 1 \text { patient with duodenal ulcer }\end{array}$ \\
\hline & & & & Measured response by fall in $\mathrm{CgA}$ \\
\hline & & & & $\begin{array}{l}\text { Durable response for unresectable NETLMs (single } \\
\text { institution) }\end{array}$ \\
\hline \multirow[t]{2}{*}{2008} & \multirow[t]{2}{*}{ Rhee et al. ${ }^{72}$} & \multirow[t]{2}{*}{42} & OS, $22-28 \mathrm{mo}$ & 6 patients experienced grade 3 toxicities \\
\hline & & & $\begin{array}{l}\text { PR or stable disease, } \\
92 \% \text { at } 6 \text { mo }\end{array}$ & $\begin{array}{l}\text { Radioembolization is a viable therapy for NETLMs with } \\
\text { acceptable toxicity (multi-institution) }\end{array}$ \\
\hline \multirow[t]{2}{*}{2009} & \multirow[t]{2}{*}{ Kalinowski et al. ${ }^{53}$} & \multirow[t]{2}{*}{9} & TTP, $11 \mathrm{mo}$ & \multirow{2}{*}{$\begin{array}{l}\text { Radioembolization is safe (acute and late toxicities low), } \\
\text { with high response rates up to } 1 \text { year even with extensive } \\
\text { tumor replacement (single institution) }\end{array}$} \\
\hline & & & $\mathrm{PR}$, in $66 \%$ at $3 \mathrm{mo}$ & \\
\hline \multirow[t]{3}{*}{2010} & \multirow[t]{3}{*}{ Saxena et al. ${ }^{73}$} & \multirow[t]{3}{*}{48} & $\mathrm{RR}, 55 \%$ & \multirow{2}{*}{$\begin{array}{l}\text { Improved survival associated with low tumor burden, } \\
\text { female sex, CR/PR, well-differentiated tumor, and absence } \\
\text { of EHD }\end{array}$} \\
\hline & & & OS, $35 \mathrm{mo}$ & \\
\hline & & & & $\begin{array}{l}\text { Radioembolization is a promising treatment for } \\
\text { unresectable NETLMs (single institution) }\end{array}$ \\
\hline \multirow[t]{3}{*}{2011} & \multirow[t]{3}{*}{ Memon et al. ${ }^{54}$} & \multirow[t]{3}{*}{40} & \multirow[t]{3}{*}{$\begin{array}{l}\text { CR, } 1.2 \%, P R, 62.7 \% \\
\text { (WHO criteria) }\end{array}$} & $\begin{array}{l}\text { ECOG performance score } 0 \text { and bilirubin }<1.2 \mathrm{mg} / \mathrm{dL} \\
\text { prognosticated better survival on MVA }\end{array}$ \\
\hline & & & & $\begin{array}{l}1-, 2-, \text { and } 3 \text {-year OS rates were } 72.5 \%, 62.5 \% \text {, and } 45 \% \text {, } \\
\text { respectively }\end{array}$ \\
\hline & & & & 3 cases of grade $3-4$ bilirubin toxicity (single institution) \\
\hline
\end{tabular}

Abbreviations: CgA, chromogranin A; CR, complete response; EHD, extrahepatic disease; MVA, multivariate analysis; NETLMs, neuroendocrine tumor liver metastases; OS, overall survival; PR, partial response; RR, relative response; TTP, time to progression.

candidates because of liver involvement. ${ }^{66}$ The ability to use a percutaneous approach allows for application in patients who are not good candidates for surgical procedures or TACE (e.g., those with hyperbilirubinemia).

\section{Conclusions}

Taken together, a variety of local and regional liverdirected approaches have shown efficacy in the management of NET liver metastases. When feasible, surgical resection for curative or debulking intent provides the most durable symptom control and overall survival, although these patients represent a highly selected favorable group. More common are patients with high tumor volume not amenable to surgery. Transplantation in these patients should still be considered investigational given the high likelihood of recurrence and limited resources available. Therefore, intraarterial regional therapies, mainly (chemo)embolization or radioembolization, are the mainstays of treatment, offering good symptom palliation and control of liver tumor burden. Larger prospective multi-institutional trials must be completed to determine the actual long-term benefit of TACE, radioembolization, and ablation therapies. The numbers of patients enrolled in TACE DEBDOX and radioembolization studies have been small in the currently published literature. Given the complexity of these patients, treatment decisions should be made in a multidisciplinary setting involving input from experienced medical oncologists, hepatologists, radiation oncologists, interventional radiologists, and surgical oncologists to best determine treatment regimens for patients with metastatic NETs to liver progression.

\section{References}

1. Modlin IM, Lye KD, Kidd M. A 5-decade analysis of 13,715 carcinoid tumors. Cancer 2003;97:934-959.

2. Perez EA, Koniaris LG, Snell SE, et al. 7201 carcinoids: increasing 
Jones et al.

incidence overall and disproportionate mortality in the elderly. World J Surg 2007;31:1022-1030.

3. Oberg K, Eriksson B. Endocrine tumors of the pancreas. Best Pract Res Clin Gastroenterol 2005;19:753-781.

4. Rindi G, D'Adda $T$, Froio E, et al. Prognostic factors in gastrointestinal endocrine tumors. Endocr Pathol 2007;18:145149.

5. Starker LF, Carling T. Molecular genetics of gastroenteropancreatic neuroendocrine tumors. Curr Opin Oncol 2009;21:29-33.

6. McDermott EW, Guduric B, Brennan MF. Prognostic variables in patients with gastrointestinal carcinoid tumors. Br J Surg 1994;81:1007-1009.

7. Janson ET, Holmberg L, Stridsberg M, et al. Carcinoid tumors: analysis of prognostic factors and survival in 301 patients from a referral center. Ann Oncol 1997;8:685-690.

8. Frilling A, Li J, Malamutmann E, et al. Treatment of liver metastases from neuroendocrine tumours in relation to the extent of hepatic disease. Br J Surg 2009;96:175-184.

9. Madoff DC, Gupta S, Ahrar K, et al. Update on the management of neuroendocrine hepatic metastases. J Vasc Inter Radiol 2006; 17:1235-1250.

10. Frilling A, Sotiropoulos GS, Li J, et al. Multimodal management of neuroendocrine liver metastases. HPB (Oxford) 2010;12:361-379.

11. Chen $H$, Hardacre JM, Uzar A, et al. Isolated liver metastases from neuroendocrine tumors: does resection prolong survival? J Am Coll Surg 1998;187:88-92.

12. House MG, Cameron JL, Lilemoe KD, et al. Differences in survival for patients with resectable versus unresectable metastases from pancreatic islet cell cancer. J Gastrointest Surg 2006;10:138-145.

13. Yao KA, Talamonti MS, Nemcek A, et al. Indications and results of liver resection and hepatic chemoembolization for metastatic gastrointestinal neuroendocrine tumors. Surgery 2001;130:677682.

14. McEntree GP, Nagorney DM, Kvols LK, et al. Cytoreductive hepatic surgery for neuroendocrine tumors. Surgery 1990;108:1091-1096.

15. Sarmiento JM, Heywood G, Rubin J, et al. Surgical treatment of neuroendocrine metastases to the liver: a plea for resection to increase survival. J Am Coll Surg 2003;197:29-37.

16. Soreide $O$, Berstad T, Bakka A, et al. Surgical treatment as a principle in patients with advanced abdominal carcinoid tumors. Surgery 1992;111:48-54.

17. Osborne DA, Zervos EE, Strosberg J, et al. Improved outcome with cytoreduction versus embolization for symptomatic hepatic metastases of carcinoid and neuroendocrine tumors. Ann Surg Oncol 2006;13:572-581.

18. Sarmiento JM, Que FG, Grant CS, et al. Concurrent resections of pancreatic islet cell cancers with synchronous hepatic metastases: outcomes of an aggressive approach. Surgery 2002;132:976-982.

19. Norton JA, Kivlen M, Li M, et al. Morbidity and mortality of aggressive resection in patients with advanced neuroendocrine tumors. Arch Surg 2003;138:859-866.

20. Gomez D, Malik HZ, Al-Mukthar A, et al. Hepatic resection for metastatic gastrointestinal and pancreatic neuroendocrine tumors: outcome and prognostic predictors. HPB (Oxford) 2007;9:345351.

21. Chamberlain RS, Canes D, Brown KT, et al. Hepatic neuroendocrine metastases: does intervention alter outcomes? J Am Coll Surg 2000;190:432-445.

22. Celinski SA, Nguyen KT, Steel JL, et al. Multimodality management of neuroendocrine tumors metastatic to the liver [abstract]. 2010
ASCO Gastrointestinal Cancers Symposium; January 22-24, 2010; Orlando, Florida. Abstract 234.

23. Le Treut YP, Delpero JR, Dousset B, et al. Results of liver transplantation in the treatment of metastatic neuroendocrine tumors. A 31-case French multicentric report. Ann Surg 1997;225:355-364.

24. Lehnert $T$. Liver transplantation for metastatic neuroendocrine carcinoma: an analysis of 103 patients. Transplantation 1998;66:1307-1312.

25. Rosenau J, Bahr MJ, von Wasielewski R, et al. Ki67, E-cadherin, and p53 as prognostic indicators of long-term outcome after liver transplantation for metastatic neuroendocrine tumors. Transplantation 2002;73:386-394.

26. Dousset B, Saint-Marc O, Pitre J, et al. Metastatic endocrine tumors: medical treatment, surgical resection, or liver transplantation. World J Surg 1996;20:908-915.

27. Le Treut YP, Gregoire E, Belghiti J, et al. Predictors of longterm survival after liver transplantation for metastatic endocrine tumors: an 85-case French multicentric report. Am J Transplant 2008;8:1205-1213.

28. Frilling A, Li J, Malamutmann E, et al. Treatment of liver metastases from neuroendocrine tumors in relation to the extent of extrahepatic disease. Br J Surg 2009;96:175-184.

29. Mazzaferro V, Pulvirenti A, Coppa J. Neuroendocrine tumors metastatic to the liver: how to select patients for liver transplantation? J Hepatol 2007;47:460-466.

30. Moertel CG, Johnson CM, McKuskick MA, et al. The management of patients with advanced carcinoid tumors and islet cell carcinomas. Ann Intern Med 1994;120:302-309.

31. Gupta S, Yao JC, Ahrar K, et al. Hepatic artery embolization and chemoembolization for treatment of patients with metastatic carcinoid tumors; the M.D. Anderson experience. Cancer 2003;9:261-267.

32. Roche A, Girish BV, de Baere T, et al. Trans-catheter arterial chemoembolization as first-line treatment for hepatic metastases from endocrine tumors. Eur Radiol 2003;13:136-140.

33. Steward MJ, Warbey VS, Malhotra A, et al. Neuroendocrine tumors: role of interventional radiology in therapy. Radiographics 2008;28:1131-1145.

34. Ruutiainen AT, Soulen MC, Tuite CM, et al. Chemoembolization and bland embolization of neuroendocrine tumor metastases to the liver. J Vasc Interv Radiol 2007;18:847-855.

35. Gupta S, Johnson MM, Murthy R, et al. Hepatic arterial embolization and chemoembolization for the treatment of patients with metastatic neuroendocrine tumors: variables affecting response rates and survival. Cancer 2005;104:590-602.

36. Eriksson BK, Larsson EG, Skogseid BM, et al. Liver embolizations of patients with malignant neuroendocrine gastrointestinal tumors. Cancer 1998;83:2293-2301.

37. Kress $\mathrm{O}$, Wagner HJ, Wied M, etal. Transarterial chemoembolization of advanced liver metastases of neuroendocrine tumors: a retrospective single-center analysis. Digestion 2003;68:94-101.

38. Marrache F, Vullierme MP, Roy C, et al. Arterial phase enhancement and body mass index are predictors of response to chemoembolization for liver metastases of endocrine tumors. Br J Cancer 2007;96:49-55.

39. Bloomston M, Al-Saif O, Klemanski D, et al. Hepatic artery chemoembolization in 122 patients with metastatic carcinoid tumor: lessons learned. J Gastrointest Surg 2007;11:264-271.

40. Sward C, Johanson V, Nieveen van Dijkum E, et al. Prolonged 
Liver-Directed Therapies in Advanced NETs

survival after hepatic artery embolization in patients with midgut carcinoid. Br J Surg 2009;96:517-521.

41. de Baere $T$, Deschamps F, Teriitheau C, et al. Transarterial chemoembolization of liver metastases from well-differentiated gastroenteropancreatic endocrine tumors with doxorubicin-eluting beads: preliminary results. J Vasc Interv Radiol 2008;19:855-861.

42. Whitney R, Valek V, Fages JF, et al. Transarterial chemoembolization and selective internal radiation for the treatment of patients with metastatic neuroendocrine tumors: a comparison of efficacy and cost. Oncologist 2011;16:594-601.

43. Gaur SK, Friese JL, Sadow CA, et al. Hepatic artery chemoembolization using drug-eluting beads in gastrointestinal neuroendocrine tumor metastatic to the liver. Cardiovasc Intervent Radiol 2011;34:566-572.

44. Kuhlmann JB, Euringer W, Spangenberg HC, et al. Treatment of unresectable cholangiocarcinoma: conventional transarterial chemoembolization compared with drug eluting beadtransarterial chemoembolization and systemic chemotherapy. Eur J Gastroenterol Hepatol, in press.

45. Kim W, Clark TW, Baum RA, Soulen MC. Risk factors for liver abscess formation after hepatic chemoembolization. J Vasc Interv Radiol 2001;12:965-968.

46. Alexander HR, Butler CC. Development of isolated hepatic perfusion via the operative and percutaneous techniques for patients with isolated and unresectable liver metastases. Cancer J 2010;16:132-141.

47. Grover AC, Libutti SK, Pingpank JF, et al. Isolated hepatic perfusion for the treatment of patients with advanced liver metastases from pancreatic and gastrointestinal neuroendocrine neoplasms. Surgery 2004;136:1176-1182.

48. Kennedy AS, Dezarn WA, McNeillie P, et al. Radioembolization for unresectable neuroendocrine hepatic metastases using resin 90-Y microspheres: early results in 148 patients. Am J Clin Oncol 2008;31:271-279.

49. Salem R, Thurston KG. Radioembolization with yttrium-90 microspheres: a state-of-the-art brachytherapy treatment for primary and secondary liver malignancies: part 3: comprehensive literature review and future direction. J Vasc Interv Radiol 2006;17:1571-1593.

50. Murthy R, Kamat P, Nunez R, et al. Yttrium-90 microsphere radioembolotherapy of hepatic metastatic neuroendocrine carcinomas after hepatic arterial embolization. J Vasc Interv Radiol 2008;19:145-151.

51. King J, Quinn R, Glenn DM, et al. Radioembolization with selective internal radiation microspheres for neuroendocrine liver metastases. Cancer 2008;113:921-929.

52. McStay MK, Maudgil D, Williams M, et al. Large-volume liver metastases from neuroendocrine tumors: hepatic intraarterial 90Y-DOTA-lanreotide as effective palliative therapy. Radiology 2005;237:718-726.

53. Kalinowski M, Dressler M, Konig A, et al. Selective internal radiotherapy with Yttrium-90 microspheres for hepatic metastatic neuroendocrine tumors: a prospective single center study. Digestion 2009;79:137-142.

54. Memon K, Lewandowski RJ, Mulcahy MF, et al. Radioembolization for neuroendocrine liver metastases: safety, imaging, and long-term outcomes. Int J Radiation Oncol Bio Phys, in press.

55. Mulier S, Ni Y, Jamart J, et al. Local recurrence after hepatic radiofrequency coagulation: multivariate metaanalysis and review of contributing factors. Ann Surg 2005;242:158-171.

56. Eisele RM, Neumann U, Neuhaus P, Schumacher G. Open surgical is superior to percutaneous access for radiofrequency ablation of hepatic metastases. World J Surg 2009;33:804-811.

57. Mazzaglia PJ, Berber E, Milas M, Siperstein AE. Laparoscopic radiofrequency ablation of neuroendocrine liver metastases: a 10-year experience evaluating predictors of survival. Surgery 2007;142:10-19.

58. Berber E, Flesher N, Siperstein AE. Laparoscopic radiofrequency ablation of neuroendocrine liver metastases. World J Surg 2002;26:985-990.

59. Gillams A, Cassoni A, Conway G, et al. Radiofrequency ablation of neuroendocrine liver metastases: the Middlesex experience. Abdom Imaging 2005;30:435-441.

60. Henn AR, Levine EA, McNulty W, et al. Percutaneous radiofrequency ablation of hepatic metastases for symptomatic relief of neuroendocrine symptoms. AJR Am J Roentgenol 2003;181:1005-1010.

61. Wessels FJ, Schell SR. Radiofrequency ablation treatment of refractory carcinoid hepatic metastases. J Surg Res 2001;95:8-12.

62. Yamakado $K$, Nakatsuka $A$, Ohmori $S$, et al. Radiofrequency ablation combined with chemoembolization in hepatocellular carcinoma: treatment response based on tumor size and morphology. J Vasc Interv Radiol 2002;13:1225-1232.

63. Boutros C, Somasundar P, Garrean S, et al. Microwave coagulation therapy for hepatic tumors: review of the literature and critical analysis. Surg Oncol 2010;19:e22-32.

64. Maithel SK, Fong Y. Hepatic ablation for neuroendocrine tumor metastases. J Surg Oncol 2009;100:635-638.

65. Gamblin TC, Christians K, Pappas SG. Radiofrequency ablation of neuroendocrine hepatic metastasis. Surg Oncol Clin N Am 2011;20:273-279.

66. Mazzaglia PJ, Berber E, Siperstein AE. Radiofrequency thermal ablation of metastatic neuroendocrine tumors in the liver. Curr Treat Options Oncol 2007;8:322-330.

67. Strosberg JR, Choi J, Cantor AB, Kvols LK. Selective hepatic artery embolization for treatment of patients with metastatic carcinoid and pancreatic endocrine tumors. Cancer Control 2006;13:72-78.

68. Ho AS, Picus J, Darcy MD, et al. Long-term outcome after chemoembolization and embolization of hepatic metastatic lesions from neuroendocrine tumors. AJR Am J Roentgenol 2007;188:1201-1207.

69. Pitt SC, Knuth J, Keily JM, et al. Hepatic neuroendocrine metastases: chemo- or bland-embolization? J Gastrointest Surg 2008;12:1951-1960.

70. Christante D, Pommier S, Givi B, Pommier R. Hepatic artery chemoinfusion with chemoembolization for neuroendocrine cancer with progressive hepatic metastases despite octreotide therapy. Surgery 2008;144:885-893.

71. Dong XD, Carr BI. Hepatic artery chemoembolization for the treatment of liver metastases from neuroendocrine tumors: a long-term follow-up in 123 patients. Med Oncol 2011;28(Suppl 1):S286-290.

72. Rhee TK, Lewandowski RJ, Liu DM, et al. 90 Y radioembolization for metastatic neuroendocrine liver tumors: preliminary results from a multi-institutional experience. Ann Surg 2008;247:1029_ 1035.

73. Saxena A, Chua TC, Bester L, et al. Factors predicting response and survival after yttrium-90 radioembolization of unresectable neuroendocrine tumor liver metastases: a critical appraisal of 48 cases. Ann Surg 2010;251:910-916. 
Jones et al.

\section{CME Activity: Neuroendocrine Tumors}

To obtain credit, you should first read the journal article. After reading the article, you should be able to answer the following, related, multiplechoice questions. To complete the questions (with a minimum $70 \%$ passing score) and earn continuing medical education (CME) credit, please go to www. medscape.org/journal/jnccn.

Credit cannot be obtained for tests completed on paper, although you may use the worksheet below to keep a record of your answers. You must be a registered user on Medscape.org. If you are not registered on Medscape.org, please click on the New Users: Free Registration link on the left hand side of the website to register.

Only one answer is correct for each question. Once you successfully answer all post-test questions you will be able to view and/or print your certificate.
For questions regarding the content of this activity, contact the accredited provider, CME@medscape.net. For technical assistance, contact CME@webmd.net.

American Medical Association's Physician's Recognition Award (AMA PRA) credits are accepted in the U.S. as evidence of participation in CME activities. For further information on this award, please refer to http://www.ama-assn.org/ama/pub/ category/2922.html. The AMA has determined that physicians not licensed in the U.S. who participate in this CME activity are eligible for AMA PRA Category 1 Credits $^{\mathrm{TM}}$. Through agreements that the AMA has made with agencies in some countries, AMA PRA credit may be acceptable as evidence of participation in CME activities. If you are not licensed in the U.S., please complete the questions online, print the AMA PRA CME credit certificate, and present it to your national medical association for review.

1. You are seeing a 64-year-old man with a new diagnosis of carcinoid tumor. What can you tell him is the most important prognostic factor for survival in cases of neuroendocrine tumors (NETs)?
A. Age over 60
B. Primary tumor location in the ileum
C. Poor baseline functional status
D. The presence of liver metastases

2. The patient is found to have liver metastases, and he is interested in surgical treatment for the metastases. What can you tell him?

A. Surgical resection, when feasible, is the optimal treatment for liver metastases

B. The presence of resectable liver metastases does not affect survival outcomes

C Cytoreductive hepatectomy does not generally improve hormone-related symptom relief

D. The degree of tumor involvement in the liver does not affect the clinical success of surgery

3. What should you consider regarding the option of transcatheter arterial embolization (TAE) and trans-

\section{Activity Evaluation}

1. The activity supported the learning objectives. Strongly Disagree

$\begin{array}{lllll}1 & 2 & 3 & 4 & 5\end{array}$

2. The material was organized clearly for learning to occur.

$\begin{array}{lllrr}\text { Strongly Disagree } & & \text { Strongly Agree } \\ 1 & 2 & 3 & 4 & 5\end{array}$

3. The content learned from this activity will impact my practice. Strongly Disagree $\begin{array}{lllll}1 & 2 & 3 & 4 & 5\end{array}$

4. The activity was presented objectively and free of commercial bias.

Strongly Disagree
1
2
3

To obtain credit, visit Medscape online at http://www.medscape.org/journal/jnccn. 